\title{
Prenatal diagnosis: a problem in verification
}

\author{
GERTRUDE KOHN, ASHER ORNOY, and MAIMON M. COHEN \\ Departments of Human Genetics and Anatomy, Hadassah-Hebrew University Medical Center, ferusalem, Israel \\ Summary. Prenatal diagnosis of chromosomal or biochemical disorders \\ demands corroboration from fetal tissues. The presence of viable maternal \\ lymphocytes in the fetal cord blood of the case presented demonstrates that, in \\ spite of the availability of this tissue, it does not always provide sufficient \\ evidence for such corroboration.
}

Prenatal cytogenetic diagnosis based on cultured amniotic fluid cells demand confirmation from other fetal tissues in the event of pregnancy termination. Various fetal tissues, including cord blood, have been utilized for such cytogenetic confirmation. We wish to report a hazard which may be encountered in the use of fetal blood for such verification.

Partial trisomy 15 (Fig. 1a) was diagnosed by amniocentesis during the 16th week of the fourth pregnancy of a mother known to carry a balanced $4 / 15$ translocation (Fig. 1b). The proposita of this family was a severely retarded 4 year old with partial trisomy 15 (to be reported in detail elsewhere). As a result of the cytogenetic findings, termination of pregnancy, 23 days later (19 weeks' gestation), was induced by hypertonic urea. A macerated fetus (histologically confirmed) was delivered 18 hours following the infusion. The placenta was not expelled spontaneously and was removed manually.

Culture of the following fetal tissues was attempted: cord blood obtained at the bifurcation of the umbilical vein on the chorionic plate; fetal side of the placenta; amnion; skin; lung, and intestine. The only successful cultures were derived from cord blood and placenta. In 30 metaphases analysed from cord blood, all had a karyotype identical to that of the carrier mother $46, \mathrm{XX}, \mathrm{t}(4 \mathrm{p}+; 15 \mathrm{q}-)$. No metaphases of $47, X X,+(15 q-)$, as seen in all cells of the amniotic fluid culture, were observed. However, chromosome analysis of fetal placenta revealed only cells with the partially trisomic karyotype (Table I).

Histological examination of the placenta revealed subchorionic necrosis with typical villi which, in some areas, appeared structurally normal with a covering of syncitium and a few cytotrophoblastic

Received 28 November 1973.
TABLE I

KARYOTYPES OBSERVED IN FAMILY MEMBERS

\begin{tabular}{|c|c|c|}
\hline & Cells Examined & Karyotypes \\
\hline \multirow[t]{2}{*}{$\begin{array}{l}\text { Proposita } \\
\text { Mother } \\
\text { Amniotic fluid } \\
\text { Fetus }\end{array}$} & \multirow{2}{*}{$\begin{array}{l}\text { Lymphocytes } \\
\text { Lymphocytes } \\
\text { Cultured fibroblasts } \\
\text { Cord blood } \\
\text { lymphocytes } \\
\text { Placenta }\end{array}$} & $\begin{array}{l}47, X X,+15 q- \\
46, X X, t(4 p+; 15 q-) \\
47, X X,+15 q-\end{array}$ \\
\hline & & $\begin{array}{l}46, X X, t(4 p+; 15 q-) \\
47, X X,+15 q-\end{array}$ \\
\hline
\end{tabular}

cells, while in others, the villi were avascular with hypercellularity. Scattered throughout the stroma of the villi were atypical large cells some of which were multinucleated. Severe congestion was observed in many villi with occasional extravasation of blood filling the stroma (Fig. 2). The trophoblastic covering was absent and the walls of congested fetal vessels were ruptured in some areas leading to fetal and maternal blood being contiguous in the intervillous spaces thereby increasing the possibility of intermingling of fetal and maternal circulation.

It is generally accepted that under normal conditions fetal and maternal circulations are entirely separate. However, in the latter stages of pregnancy, mixing of maternal and fetal blood may occur in some cases (Zarou, Lichtman, and Hellman, 1964). The likelihood of such an event may be increased by damage to placental villi or intrauterine fetal death. Histological examination of the placenta and fetal tissues in the present case showed that the fetus died several days before the instillation of hypertonic urea. Cord blood, for confirmation of the karyotype observed in cultured amniotic fluid cells, was obtained, therefore, several days after fetal death had occurred. Admixture of maternal and fetal circulation was strongly suggested by the ob- 

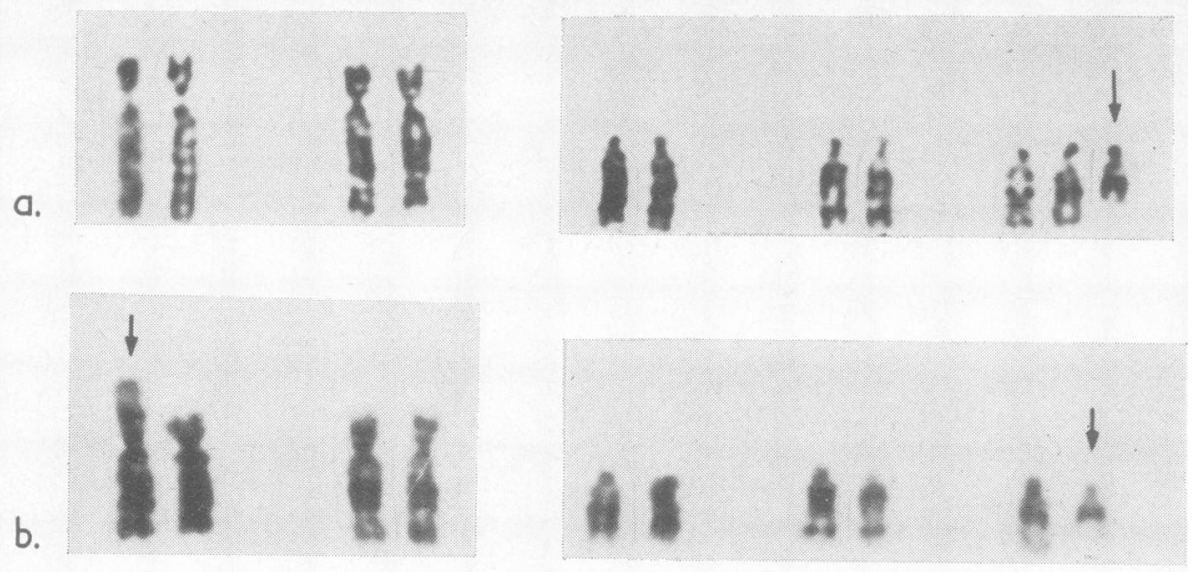

4-5

$13-15$

Fig. 1. Line a: Partial karyotype of the proposita. Banding obtained following trypsin pretreatment. Note 'partial trisomy' of chromosome No. 15.

Line b: Partial karyotype of the mother illustrating a 'balanced translocation', $46, \mathrm{XX}, \mathrm{t}(4 \mathrm{p}+; 15 q-)$.

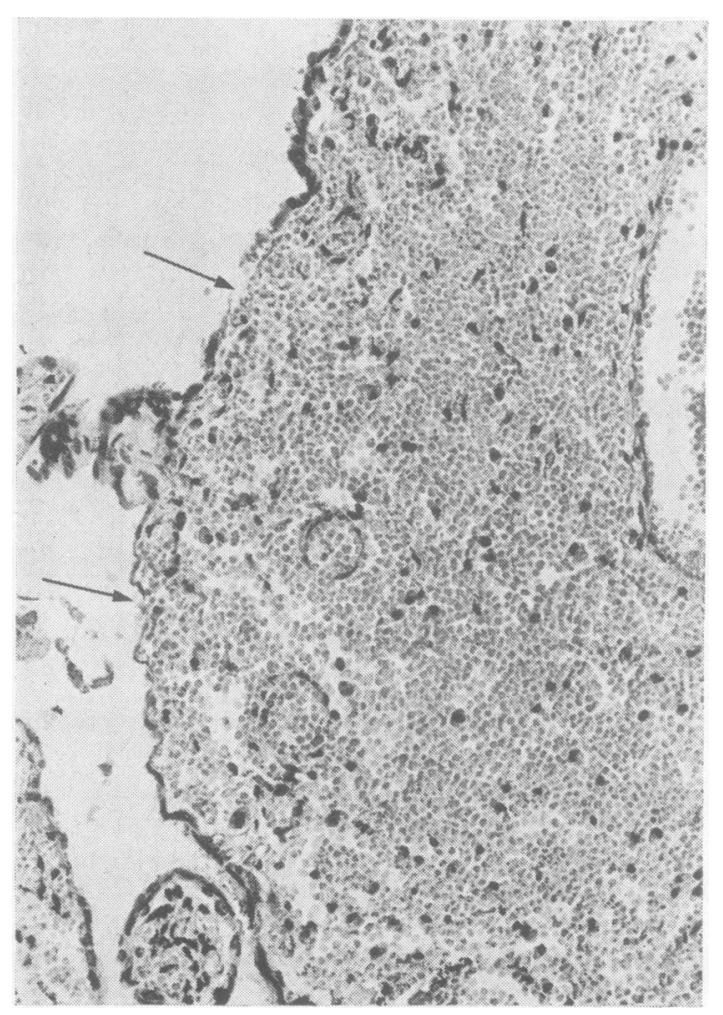

FIG. 2. Microphotograph of villus showing severe congestion and extravasation of fetal erythrocytes. Note very thin trophoblastic covering which in some areas is completely absent (arrows). (H \& E, 200.) servation that only maternal lymphocytes responded to PHA (confirmed cytogenetically) and fetal lymphocytes, if still present, were no longer viable. Since delayed separation of the placenta also occurred and chord blood was obtained near the site of placental attachment, the probability of $f$ maternal blood entering fetal vessels may have been increased.

Subchorionic intervillous thrombosis and necrosis of chorionic villi beneath the chorionic plate have been found in placentae of abortuses induced by infusion into the amniotic sac of hypertonic saline (Bengtsson and Stormby, 1962) or hypertonic urea (our personal observation). Following such procedures massive subchorionic infiltration of neutrophils and lymphocytes, most probably of maternal origin, occurs. The latter cells could have reached the fetal circulation and thus have been recovered in cultures of fetal cord blood. Similar necrosis and chorionic infiltration were noted in the placenta of the present case. In view of the above observations, fetal cord blood alone should not be considered sufficient for corroboration of prenatal diagnoses and additional cultured fetal tissues must also be examined for such confirmation.

\section{REFBRENCES}

Bengtsson, L. P. and Stormby, N. (1962). The effect of intraamniotic injection of hypertonic sodium chloride in human midpregnancy. Acta Obstetricia et Gynecologia Scandinavica, 41, 115123.

Zarou, D. M., Lichtman, H. C., and Hellman, L. M. (1964). The transmission of chromium-51 tagged maternal erythrocytes from mother to fetus. American fournal of Obstetrics and Gynecology, 88, 565-571. 